\title{
Uma análise de relatos verbais de alunas sobre situações de assédio sexual no contexto universitário
}

\author{
An analysis of female students' verbal accounts concerning situations of \\ sexual harassment in the university context \\ Un análisis de relatos verbales sobre situaciones de acoso sexual en el \\ contexto universitário
}

Yana Linhares ${ }^{1}$, Carolina Laurenti ${ }^{2}$

[1][2] Universidade Estadual de Maringá I Título abreviado: Assédio sexual no contexto universitário | Endereço para correspondência: Carolina Laurenti. Departamento de Psicologia (bloco 118, sala 04). Universidade Estadual de Maringá, Avenida Colombo, 5790 - Jardim Universitário - Maringá - PR - CEP: 87020900 | Email: yana-linhares@hotmail.com I doi: 10.18761/PAC.2018.n2.08 | Financiamento: este trabalho foi financiado por meio de bolsa de iniciação científica da Fundação Araucária (processo número: 3242/2017), recebida pela primeira autora.

Resumo: A dominação masculina é uma prática cultural que pode ser verificada em diferentes contextos, inclusive na universidade, como ilustrado nos casos de assédio sexual cometidos por professores contra alunas. O objetivo desta pesquisa foi investigar práticas de dominação masculina no ambiente universitário por meio da análise de relatos verbais de alunas postados em uma página do Facebook intitulada "Meu professor abusador", utilizada para explicitar comportamentos abusivos emitidos por professores no âmbito educacional formal. Foram realizadas análises de 93 relatos que descreviam situações de abuso, perpetrados por professores universitários. Os principais aspectos identificados nos relatos foram: comportamentos abusivos na forma de brincadeiras e piadas; estereótipos de professores abusadores; 0 caráter gradativo do abuso; proposta de sexo em troca de notas, ilustrando o manejo de reforçadores e punidores típicos do contexto universitário. Foram descritos os efeitos dos abusos para o percurso acadêmico das alunas, como desistir de matérias, projetos, e da própria vida acadêmica; e também os comportamentos das alunas perante o abuso, com destaque para o comportamento de aquiescer, que pode acabar reforçando o comportamento abusivo do professor. Ressalta-se a importância da denúncia e da criação de instâncias na universidade que possam acolher, encaminhar, discutir e prevenir casos de assédio sexual.

Palavras-chave: violência de gênero; assédio sexual; professor universitário; alunas; análise do comportamento 


\begin{abstract}
Masculine domination is a cultural practice identified in various contexts, including the academic one, as illustrated by the cases of sexual harassment by male professors towards female students. This research aimed to scrutinize masculine domination practices in the academic environment by analyzing verbal accounts students posted on a Facebook page entitled "My abuser professor", employed to specify abusive behaviors by male professors in the formal education. We conducted functional analysis from 93 accounts, which described situations of harassment in the academic scenario, out of such we identified: abusive behaviors disguised as jokes; stereotype of abusive professors; the gradual nature of the harassment; the offer of sex in exchange for grades evincing the use of contingencies of reinforcement and punishment known to the academic world. We described the effects that such abuses had for the students' academic course, making them abandon subjects, research projects and even academic life itself; as well as the students' behavior towards the abuser, distinctively the behavior of acquiescence, which may end up reinforcing the professor's abusive behavior. We emphasize the importance of reporting said behaviors, as well as fostering administrative bodies in the University able to embrace, advance and discuss cases of sexual harassment.
\end{abstract}

Keywords: gender violence; sexual harassment; college professor; students; behavior analysis

Resumen: La dominación masculina es una práctica cultural que se verifica en diversos contextos, incluyo en el universitario, tal cual lo muestran los casos de acoso sexual cometidos por profesores contra alumnas. Este estudio trato de investigar las prácticas de dominación masculina en el ambiente universitario por medio del análisis de relatos verbales de alumnas publicados en un sitio del Facebook intitulado "Mi profesor acosador", utilizado para explicitar conductas abusivas emitidas por profesores en el ámbito de la educación formal. Se realizaron análisis funcionales de 93 relatos que describían situaciones de abuso en el ambiente universitario, a partir de las cuales se identificaron: conductas abusivas en forma de broma y chistes; estereotipos de profesores abusadores; el carácter gradual del abuso; el planteo de sexo a cambio de notas ilustrando el manejo de reforzadores y de la punición típica del contexto universitario. Se describieron los efectos de los abusos al trayecto académico de las alumnas, como abandonar asignaturas, proyectos y hasta la propia vida académica; $y$ las conductas de las alumnas delante del abuso, destacando la conducta de condescender o callar, lo que puede terminar por reforzar la conducta abusiva del profesor. Se resalta la importancia de la denuncia, bien como la creación de instancias en la Universidad que acojan, direccionen y discutan los casos de acoso sexual.

Palabras-clave: violencia de género; el acoso sexual; profesor universitario; estudiantes; análisis de la conducta 
Em termos analítico-comportamentais, a dominação masculina (Bourdieu, 1998/2010) pode ser entendida como um conjunto de práticas culturais mantidas de geração em geração por meio do controle social, no qual são manipulados reforçadores e punidores, de modo a estabelecer um acesso e distribuição desigual entre os gêneros, favorecendo o masculino. No âmbito das contingências sociais que constituem essas práticas, são reforçados comportamentos que tenham como função a manutenção dessa desigualdade e punidos, ou colocados em extinção, comportamentos que tenham como função estabelecer uma relação mais igualitária entre os gêneros. Essa forma de controle social impede ou dificulta o estabelecimento de práticas e repertórios comportamentais que contribuam para o enfrentamento e superação desse controle por parte das mulheres.

De acordo com Bourdieu (1998/2010), a dominação masculina tornou-se "naturalizada". Isso quer dizer que o caráter histórico dessa dominação é obscurecido por práticas culturais que justificam a desigualdade entre homens e mulheres com base em diferenças sexuais biologicamente estabelecidas. Nesse processo, são ignoradas as formas de controle social dessa dominação, as quais são pautadas em sistemas de reforçamento que geram padrões comportamentais (gênero) e sentimentos associados a esses padrões (identidade de gênero) que beneficiam os homens em detrimento das mulheres (Silva \& Laurenti, 2016).

Não apenas os homens, mas as próprias mulheres podem contribuir para o fortalecimento de práticas culturais de dominação masculina (Bourdieu, 1998/2010), já que alguns reforçadores sociais como atenção, aprovação e afeição só são produzidos quando as mulheres apresentam comportamentos consistentes com o estereótipo feminino de delicadeza, sensibilidade, abnegação, passividade e submissão. Semelhantemente, comportar-se em conformidade com esses padrões pode se dar também por reforçamento negativo, tendo como função evitar ou eliminar eventos aversivos sociais como desaprovação, desprezo, insulto. Assim, longe de serem esclarecidos por uma essência masculina ou feminina, ou por aspectos estritamente anatomofisiológicos, os estereótipos de masculinidade e feminilidade são explicados por práticas culturais que geram, por meio de controle de estímulos, consequências diferenciais para comportamentos de homens e mulheres, acarretando, no âmbito das práticas culturais de dominação masculina, não apenas diferenças entre os gêneros, mas também desigualdades (Freitas \& Morais, 2019; Ruiz, 2003; Silva \& Laurenti, 2016).

$\mathrm{Na}$ perspectiva skinneriana, o fortalecimento e manutenção de práticas culturais depende, dentre outros aspectos, da sua transmissão entre as gerações (Skinner, 1971/1973). As práticas culturais de dominação masculina ainda se mantêm porque também foram e são difundidas por formas de controle social que desempenham um papel central na transmissão de práticas culturais, como é o caso do controle institucional (ou por agências de controle).

Uma das agências de controle que contribui para a perpetuação de práticas culturais de dominação masculina é a educação, inclusive a educação formal propiciada pelo contexto universitário. Segundo Porto (2017), a violência de gênero - uma das expressões das práticas culturais de dominação masculina - não é plenamente reconhecida na universidade, pois, sendo um espaço de pessoas consideradas intelectualmente privilegiadas, supõe-se que ele seria incompatível com a perpetuação de formas de violência, inclusive contra as mulheres. No entanto, o que se verifica é um cenário diferente: tem havido um avanço cada vez maior da violência de gênero nos campi universitários brasileiros, como pode ser constatado na ocorrência de trotes violentos, nos casos de assédio sexual e moral, estupros e, até mesmo, assassinatos (Bandeira, 2017).

A despeito de a pesquisa nacional sobre o assunto ser ainda bastante incipiente (Bandeira, 2017), alguns estudos têm indicado dados alarmantes. Por exemplo, uma pesquisa realizada no Brasil, em 2015, com 1.823 universitários de ambos os sexos (60\% mulheres e $40 \%$ homens), de todas as regiões, destacou que, entre as universitárias entrevistadas, $67 \%$ afirmaram já ter sofrido algum tipo de violência no contexto universitário, seja ela sexual, psicológica, moral ou física. Cerca de 56\% já sofreram assédio sexual, e $28 \%$ violência sexual, o que incluiria estupro, tentativa de abuso quando sob efeito de álcool, ser tocada sem consentimento 
ou ser forçada a beijar um veterano (Data Popular/ Instituto Avon, 2015).

Além disso, a violência sexual na universidade pode ser cometida por professores e não só por outros estudantes. Reilly, Lott e Gallogly (1986) apresentaram diversos dados acerca dos casos de assédio sexual nas universidades americanas. De acordo com os autores, um dos primeiros estudos sobre o assunto destacou que entre 400 mulheres entrevistadas na universidade de Berkeley, 20\% foram assediadas por um professor na universidade, sendo que $20 \%$ das alunas transferidas relataram ter passado pela mesma situação em sua antiga universidade. Outras duas pesquisas realizadas na Universidade da Carolina mostraram que, em ambas, as mulheres passaram por situações de contato físico sem consentimento $(7,8 \%$ e $8,9 \%)$, sendo que, na segunda pesquisa, cerca de $20 \%$ das mulheres sofreram assédio verbal de seus professores. Fitzgerald et al. (1988) também trazem dados de uma pesquisa abrangente de assédio sexual nos EUA, mostrando que $42 \%$ das 10.644 mulheres entrevistadas relataram ter sido alvo de assédio sexual de professores nos seus 2 anos de estudos.

De acordo com Almeida (2017), o professor possui uma posição de autoridade no meio educacional, julgando, avaliando e participando da formação de novas gerações que estão em processo de construção e de formação de conhecimento. Portanto, seus comportamentos podem ser considerados modelo para a reavaliação de condutas machistas e sexistas dos alunos. Nesse sentido, casos de assédio cometidos por professores auxiliam ainda mais na perpetuação de práticas de dominação masculina, considerando que há uma transmissão e uma provável reprodução dessas práticas por parte dos seus alunos. Além disso, os professores podem usufruir de seus privilégios na universidade como forma de controle coercitivo (Sidman, 1989/2009), manipulando reforçadores e punidores associados ao domínio acadêmico com a função de silenciar e ameaçar as alunas, dificultando a denúncia por parte delas. Conforme destacado por Costa (2016), as situações de abuso sexual de professores contra alunas são tratadas pela universidade de modo bastante burocrático, o que atrasa ou impede ações rápidas e efetivas, dando margem à impunidade e perpetuação desse tipo de prática.
Nesse contexto, formas alternativas de compartilhamento e de denúncia de casos de abuso na esfera acadêmica têm sido utilizadas. Uma delas, que ganhou destaque neste estudo, foi a página do Facebook "Meu professor abusador". Segundo o jornal Estadão, de São Paulo, na reportagem de Palhares (2016), a página teria sido criada por três amigas de Porto Alegre e teria recebido por volta de 600 relatos em três dias. Os casos foram relatados por alunas de todo Brasil que estiveram envolvidas em algum caso de abuso perpetrado por seus professores, em diferentes etapas do processo educacional, sendo desde o ensino básico, cursinhos, até o ensino superior, tanto em instituições privadas quanto públicas. Nessas denúncias era sugerido, pelas gerenciadoras da própria página, que o nome do professor não fosse citado, apenas a instituição e uma descrição das práticas de violência contra as alunas.

As redes sociais, de modo geral, bem como as páginas de denúncia como a do "Meu professor abusador", são importantes fontes de identificação de comportamentos e práticas culturais, já que contêm informações relevantes sobre como se dão as relações sociais atuais em diferentes âmbitos (Alcará, Chiara \& Tomaél, 2005), gerando registros que podem também ser fontes de investigação e estudos de interações e conversações em pequena e larga escala (Recuero, 2014). Considerando esse panorama, o objetivo deste estudo foi reconhecer e descrever as contingências de dominação masculina no contexto universitário, por meio de uma análise de aspectos comportamentais e contextuais identificados nos relatos publicados na página "Meu professor abusador".

\section{Método}

Foi realizada uma pesquisa documental, cujas fontes foram relatos de jovens universitárias extraídos da página da rede social Facebook "Meu professor abusador". O último relato a ser postado foi no dia 27 de fevereiro de 2016 e a última publicação da página foi no dia 3 de abril de 2016. Foram analisados somente os relatos que apresentaram compor- 
tamentos de assédio sexual ${ }^{1}$ emitidos por professores no contexto universitário como ofensa verbal (cantadas, xavecos, brincadeiras e comentários sexistas), contato físico sem consentimento (como mão na coxa, tentativa de beijo e entre outros), ou outra forma de abuso que pudesse prejudicar o desempenho acadêmico das alunas em vista da sua condição de mulher. Foram excluídos os relatos que se referiam a: outros graus de escolarização como o Ensino Fundamental e Médio, e cursinhos; professores de outras instituições como cursos de inglês, por exemplo; outros comportamentos que não o de assédio; casos de abuso que não eram cometidos por professores.

As informações descritas em cada caso foram organizadas seguindo estes parâmetros: transcrição do caso conforme postado na página; descrição das contingências envolvidas no caso, buscando identificar os aspectos comportamentais (ação-topografia) e os aspectos contextuais (situação antecedente e consequências) referentes tanto aos comportamentos abusivos do professor quanto aos comportamentos das alunas perante esses comportamentos abusivos; análise preliminar do caso em pauta, valendo-se de conceitos e princípios analítico-comportamentais. A sistematização dos relatos com base nesse esquema orientou a construção de

1 Judicialmente, o crime de assédio sexual consta no Código Penal Brasileiro (1940) no Título IV, Dos Crimes Contra a Dignidade Sexual, no Capítulo I, Dos Crimes Contra a Liberdade Sexual, no Artigo 216-A. De acordo com o Código, entende-se por assédio sexual "Constranger alguém com o intuito de obter vantagem ou favorecimento sexual, prevalecendo-se o agente da sua condição de superior hierárquico ou ascendência inerentes ao exercício de emprego, cargo ou função" (Código Penal, 1940, p. 54). O termo "abuso", no Código Penal Brasileiro (1940), é apenas utilizado no Capítulo IV, Do Estelionato e Outras Fraudes, Abuso de Incapazes, no Artigo 173. No entanto, no Dicionário Crítico do Feminismo (2009), abuso sexual é definido como "todas as condutas de natureza sexual, quer sejam de expressão física, verbal ou não verbal, propostas ou impostas a pessoas contra a sua vontade, principalmente em seu local de trabalho, e que acarretam um ataque à sua dignidade" (Hirata et al., 2009). Considerando a definição de assédio sexual conforme o Código Penal, e a noção de abuso sexual de acordo com o Dicionário Crítico do Feminismo, neste trabalho, esses termos serão utilizados de maneira intercambiável, pois não parecem ser inconsistentes entre si e abarcam as circunstâncias descritas pelos relatos das alunas a respeito da conduta de seus professores. categorias, que procuraram organizar e dar relevo a aspectos da descrição dos relatos que permitissem auxiliar na identificação de relações abusivas entre professores e alunas no contexto universitário.

\section{Resultados e Discussão}

Excluindo eventuais repetições e problemas de numeração da página, do total de 614 casos computados e descritos, 103 aconteceram no ambiente universitário e 93 atenderam aos critérios de seleção, ou seja, $17 \%$ do total dos casos. Ainda que, para a Análise do Comportamento (Skinner, 1953/2003), a explicação de um comportamento seja funcional e não pautada na topografia, a organização dos resultados privilegiou a descrição das principais topografias identificadas nos relatos, indicando também, quando fosse possível, a situação antecedente em que eram emitidas e as consequências. Isso porque, de um lado, entende-se que muitas das topografias envolvidas em casos de assédio sexual são socialmente aceitas, sendo usadas inclusive para deslegitimar situações de violência (Almeida, 2017). Por outro lado, considerando que diferentes topografias podem ter a mesma função, as topografias dos comportamentos abusivos dos professores, mesmo que distintas, em tese teriam função similar, qual seja, a de produzir consequências aversivas ou remover eventos reforçadores positivos contingentes a determinados comportamentos das alunas, de modo a obter algum reforçador pessoal; nesses casos, relacionado a contato sexual.

A seguir serão apresentadas algumas categorias de análise formuladas com base no exame dos relatos. Os títulos de algumas delas destacam trechos dos relatos que dão relevo às principais topografias de comportamentos abusivos mencionados pelas alunas. A transcrição dos relatos preservará a grafia original, o que esclarece eventuais imprecisões e abreviações na escrita.

\section{"É só uma "brincadeira"": as topografias socialmente aceitas do comportamento abusivo}

Do total de casos analisados, $70 \%$ deles apresentaram a descrição de algum comportamento abusivo do professor na forma de "brincadeiras" e piadas. 
Considerada supostamente inocente e socialmente aceita, esse tipo de topografia é muito mais difícil de ser identificada como uma forma de controle coercitivo.

Alguns relatos descreveram que os professores, diante de uma audiência (e.g., alunos em sala de aula), faziam piadas e "brincadeiras" comumente relacionadas à sexualidade ou aos atributos físicos das alunas, inclusive desqualificando-as intelectualmente, como no exemplo: "comentava para quem quisesse ouvir que eu, sua aluna, era burra e gostosa dizendo que quando deus me perguntou se eu queria cerebro ou coxa, eu teria respondido só coxa ta bom"'. A reação da audiência de rir diante dos comentários jocosos dos professores criava uma situação social que atenuava o caráter abusivo ao qual as alunas estavam expostas.

A despeito de serem banalizados, Almeida (2017) esclarece que esses tipos de piadas e "brincadeiras" podem ser entendidos como formas de violência que subscrevem a desigualdade entre gêneros:

Expressões verbais e gestuais que menosprezam, desvalorizam, criticam de modo negativo e pejorativo as mulheres, em especial em sala de aula, por professores, não podem ocorrer. Estas expressões, ditas às vezes em tom de brincadeira e de meras piadas, são, na verdade, expressões de violência simbólica e moral, que acabam por constranger, intimidar, humilhar, desconsiderar, ferir a dignidade de uma mulher (seja aluna, professora ou funcionária) ou mesmo de todo o contingente social identificado como mulheres. (p. 396)

A análise dos referidos trechos dos relatos das alunas permite destacar que o comportamento abusivo pode ter inúmeras topografias, até mesmo as consideradas socialmente inofensivas. Em vista disso, é preciso explicitar a função aversiva, para as mulheres, dessas "brincadeiras e piadas", como aquelas já sugeridas por Almeida (2017): "constranger, intimidar, humilhar, desconsiderar, ferir a dignidade de uma mulher" (p. 396). Esse caráter aversivo é atenuado por práticas culturais que reputam como socialmente aceitáveis tratar o corpo e a sexualidade da mulher como "objetos" de escárnio, contribuindo para a "naturalização" da inferioridade e objetificação feminina (Bourdieu, 1998/2010). Combater a dominação masculina requer que essas práticas opressivas não sejam mais transmitidas, e uma das formas de contribuir para isso é não reforçar até mesmo essas topografias de comportamentos (piadas, brincadeiras) que, em última instância, mantêm a disparidade de gênero em prejuízo da mulher.

\section{Existe um abusador típico?}

Em 26\% dos casos as alunas descreveram os professores que emitiram comportamentos abusivos recorrendo a algum estereótipo. Alguns relatos (9\%) apresentavam descrições dos professores como tendo "pinta de galã", como sendo alvos de investidas por parte das alunas, ou como já sendo conhecidos como "pegadores", como pode ser verificado no seguinte trecho: "descobri que ele tinha a fama de 'pegar' as alunas (inclusive, agora é noivo de uma)". Já em outros relatos (17\%), as alunas destacaram que os comportamentos abusivos foram emitidos por professores cujo padrão comportamental é considerado socialmente inconsistente com práticas abusivas. Esse é o caso de professores classificados como "desconstruídos", "de esquerda", "queridões" da turma; ou, ainda, professores ditos "conservadores" ou "sérios", cujo comportamento verbal geralmente destacava a importância de se conduzir a vida acadêmica com correção, supostamente evitando situações que comprometeriam uma conduta ilibada.

$\mathrm{Na}$ perspectiva analítico-comportamental, os rótulos ou traços de personalidade podem ser entendidos como comportamento verbal que descreve padrões de comportamento que são muito frequentes no repertório comportamental dos indivíduos por terem sido consistentemente reforçados (Skinner, 1953/2003). Todas essas classificações ou rótulos podem ser construídos, na esfera cotidiana, com base na observação de regularidades comportamentais. Assim, pautando-se nos rótulos é possível fazer previsões do comportamento, descrevendo uma alta probabilidade de o comportamento ocorrer novamente diante de situações semelhantes às quais o comportamento foi emitido e reforçado (Skinner, 1953/2003). Os rótulos podem, então, ser entendidos como uma regra ou autorregra (Paracampo \& Albuquerque, 2005), quando o 
falante, no caso as alunas, formulam descrições de contingências a respeito do comportamento dos professores, e tais estímulos discriminativos verbais (descrições) passam a controlar o próprio comportamento das alunas diante dos professores.

Conforme sugerem os relatos, no caso do professor "pegador" era mais provável que ele se comportasse de modo abusivo em comparação com professores designados por outros rótulos. Presumivelmente, o professor "pegador" recebeu essa classificação com base na regularidade observada das respostas que compõem essa classe operante, como se verifica no seguinte trecho: " $A$ princípio tentou virar meu amigo, no entanto não dei a mínima abertura, pois logo observei suas atitudes e soube da fama dele na Universidade". Nessa situação, o rótulo de professor "pegador" parece ter controlado o comportamento da aluna de evitar o estabelecimento de uma relação mais próxima com o professor.

Já com o professor "desconstruído" esperava-se um padrão de comportamento diferente. Culturalmente, costuma-se definir uma pessoa como "desconstruída" quando ela apresenta comportamentos considerados sem preconceitos, a favor da igualdade entre os gêneros, livre de quaisquer ideais retrógrados e conservadores e, até mesmo, um indivíduo com determinada aparência, como neste caso: "O machistinha ainda usa dread pra passar um semblante de descolado". No entanto, como sugerem os relatos, alguns comportamentos dos professores mostraram-se incompatíveis com esse estereótipo: "Apesar de sempre se dizer um cara desconstruido, de esquerda e apoiador do feminismo, é conhecido no ia como boy lixo".

Ainda conforme os relatos, situação semelhante parece ter acontecido com os professores considerados "queridões" pelos alunos: "as pessoas gostam dele porque é engraçado e carismático". Geralmente, esse padrão de comportamento é fonte de reforçadores para os comportamentos dos demais alunos no contexto de sala de aula, ou seja, os professores classificados desse modo podem ser menos exigentes, podem conversar mais com os alunos, ser mais maleáveis em relação às regras, o que pode ter contribuído para que comportamentos de abuso por parte desse professor fossem considerados improváveis: "Ele é um ótimo professor, e por isso fica di- fícil acusar ele de qualquer coisa", ou ainda: "Ele é o 'queridão' entre os alunos ... Porém, quando estamos nos formando, ele cria grupos no whats só para falar de sacanagem, vive falando e postando coisas obscenas, convida muitas alunas para ir na casa dele".

Análise similar também se aplica aos casos de professores conhecidos por serem "conservadores" e "sérios", os quais correspondem a um padrão de comportamento considerado "rígido", respeitoso e correto, mas que acabam, de acordo com alguns relatos, também emitindo comportamentos abusivos: "Ainda que seja extremamente católico, que tenha opiniões ultra-conservadoras (machistas, homofóbicas, transfóbicas), e que seja casado com filhos, assediava as alunas em troca de notas extras, e reiteradamente vinha puxar papo em redes sociais com elogios invasivos não autorizados".

O que acontece muitas vezes, como nos casos descritos acima, é a personificação das práticas de abuso por meio de rótulos, como o de professor "pegador", situando a análise de comportamentos abusivos em nível estritamente individual, como se houvesse um abusador "típico", definido por determinadas características consideradas intrínsecas a ele, dando margem a explicações internalistas do comportamento abusivo. Ademais, isso pode dar ensejo, outrossim, a explicações circulares, em que o rótulo pode acabar adquirindo uma função explicativa, de acordo com a qual o comportamento abusivo é supostamente esclarecido pelo fato de o professor ser "pegador" e a evidência de que é "pegador" recai justamente na observação de comportamentos abusivos emitidos por ele. $\mathrm{O}$ relato das alunas de se surpreenderem com a emissão de comportamentos abusivos por parte de professores "desconstruídos", "queridões" ou "conservadores" pode também ser entendido como mais uma instância da personificação de práticas abusivas, já que o controle discriminativo desses estímulos verbais (rótulos) sinalizava a emissão de comportamentos incompatíveis com aqueles de um abusador considerado "típico". Isso faz com que problemas sociais, como as práticas culturais de dominação masculina, se convertam em questões puramente individuais, ignorando a dimensão cultural que perpassa essas relações.

Não parece haver, portanto, um "abusador típico". O comportamento abusivo é resultado de 
diversas variáveis culturais e ontogenéticas, cuja inter-relação pode até apresentar alguma regularidade ou padrão. O problema é que a restrição desses comportamentos a algum tipo específico de sujeito faz com que se acredite que a punição desse indivíduo irá erradicar os comportamentos abusivos emitidos no contexto universitário, por exemplo. Isso não quer dizer, entretanto, que os comportamentos abusivos emitidos por indivíduos, inclusive por aqueles definidos pelos rótulos mencionados, não devam ser punidos, mas que o combate às práticas de dominação masculina vai além disso, requerendo formas de enfraquecer a transmissão dessas práticas na cultura. Embora, de acordo com Skinner (1971/1973), a manutenção de uma prática cultural dependa do comportamento de indivíduos particulares - o que justificaria, em alguma medida, a punição do indivíduo que emite comportamentos abusivos - a prática cultural ultrapassa o tempo de vida do indivíduo - requerendo não apenas punição para as ações de indivíduos que se comportaram de maneira abusiva, mas uma mudança em contingências sociais mais amplas, que impeçam a transmissão dessas práticas em diferentes esferas da sociedade.

\section{"Começou conversando sobre a matéria": o caráter gradual da mudança da topografia do comportamento abusivo}

Em 5\% dos relatos, as alunas descreveram que os professores iniciavam uma aproximação falando sobre a matéria, convidando-as para participar de projetos de pesquisa, como no exemplo: "Antes de eu saber desse comportamento dele, nós conversavamos bastante e eu tinha muito interesse na disciplina que ele ministrava. Sempre conversavamos somente sobre Direito e nunca dei liberdade nenhuma a respeito da minha vida pessoal". Em outro caso, a aluna relatou ter recebido elogios do professor pelos poemas que escrevia:

... gostava de escrever poemas, nada genial mas gostava. Daí que um certo professor de comunicação super conceituado na universidade leu minhas coisas numa comunidade do Orkut e veio me encher de elogios. Eu achei o máximo pq né? Um professor super elogiado, super inteligente gostar dos meus poemas.
Todavia, uma vez estabelecida a aproximação com a aluna por meio desse tipo de reforço social, o professor valia-se dessa condição para emitir comentários de cunho sexual. Dando continuidade à transcrição do relato da aluna:

... até que um dia de madrugada ele me mandou msg perguntando o que me fazia tremer e eu sem entender perguntei: 'tremer como?' e ele dizendo que eu não era ingênua e sabia o que significava. Nunca mais conversei com ele e nunca mais escrevi um poema.

$\mathrm{Na}$ descrição de outro caso semelhante a aluna relatou: "Começou com o meu orientador do doutorado me elogiando, falando como estava bonita e tal, depois começou a me chamar para um happy hours e eu sempre dizia que não podia ir até que começou a mão boba". O exame desses trechos sugere que pode haver, então, um controle inicial por reforçamento positivo por parte do professor, por meio da apresentação de eventos reforçadores sociais (aprovação social, elogios) contingentes a algum comportamento das alunas (e.g., discutir sobre a matéria e projetos, escrever poemas). Porém, uma vez estabelecida uma relação comportamental que presumivelmente sinaliza a produção de reforçadores positivos, favorecendo o estreitamento da relação professor-aluno, o professor passa, posteriormente, a emitir comentários de cunho sexual, dificultando, por parte da aluna, a identificação de uma relação de controle coercitivo.

A partir dessa topografia inicial, associada a reforçadores positivos sociais, o comportamento abusivo dos professores passou a exibir topografias mais conspícuas e agressivas, na forma de contato físico (toque), de acordo com $27 \%$ dos relatos. Essas topografias podem ocorrer na presença somente da aluna: "Fui a última a terminar a prova e fiquei sozinha com ele na sala de aula, quando ele fechou a porta. Sentou ao meu lado enquanto eu tentava resolver a prova, começou a passar a mão na minha coxa"; mas elas também podem ocorrer diante de outras pessoas, de modo mais discreto, sem que outros alunos percebessem:

Ele leciona apenas uma matéria e durante uma delas, este mesmo professor sentou ao meu lado 
no microscópio e me pediu uma pinça, para mostrar algo ao meu colega. Até aí tudo bem, foi quando me dei conta que ele estava com uma das mãos na minha coxa, acariciando ela. Entrei em desespero na hora, pedi para agilizassem em trazer a tal pinça, pois enquanto não a traziam, ele continuava com a mão em mim.

Esse tipo de controle caracterizado pela apresentação imediata de reforçadores positivos associada à apresentação posterior de eventos aversivos também configura um tipo de controle coercitivo. Segundo Skinner (1971/1973) e Sidman (1989/2009), o controle coercitivo baseado somente em punição e reforçamento negativo produz uma série de efeitos colaterais e consequências aversivas a curto prazo, tornando mais explícito esse tipo de controle e facilitando o contracontrole. Já o controle por reforçamento positivo pode funcionar como uma técnica mais eficaz de controle coercitivo, uma vez que, de acordo com Skinner (1971/1973), ele não é tão evidente quanto as técnicas que se utilizam da apresentação de eventos aversivos imediatos. Portanto, por apresentar consequências aversivas postergadas, esse tipo de controle pode ser mais vantajoso para o agente controlador. No caso dos professores, então, a emissão de comportamentos por parte deles que produzam reforçadores positivos aos comportamentos das alunas torna o controle opressivo menos explícito, de modo a dificultar formas de enfrentamento desse tipo de controle, possibilitando, ainda, a emissão de comportamentos que produzam eventos aversivos às alunas de maneira postergada.

\section{"Sexo em troca de aprovação": os reforçadores e punidores do contexto acadêmico}

Em 20\% dos acasos, as alunas descreveram que o professor se comportou de maneira a desqualificá-las em relação ao meio acadêmico, propondo sexo em troca de notas. Esse tipo de topografia é comum nos contextos educacionais, uma vez que o professor tem a possibilidade de estabelecer relações de controle opressivo por meio da manipulação de reforçadores e punidores dos quais ele dispõe institucionalmente, e que praticamente impossibilitam o contracontrole por parte das alunas.
Nesse contexto são reforçados comportamentos de obediência, sendo que a aluna deve acatar o que o professor disser com a função de fugir ou evitar o contato com eventos aversivos manipulados pelo professor. De acordo com Skinner (1953/2003), a obediência é o produto de uma técnica de controle associada à punição. É especificado um comportamento que deve ser emitido e se estabelece uma condição aversiva em que somente com a emissão desse comportamento se possibilita a eliminação ou evitação do evento aversivo. Em relação aos casos, os relatos sugerem que são estabelecidas contingências para que a aluna somente evite o evento aversivo, que seria a reprovação, por meio da aceitação da proposta de cunho sexual do professor. $\mathrm{Da}$ mesma forma, negar-se a fazê-lo pode gerar ainda mais eventos aversivos como a constante ameaça por parte do professor, o que poderia levar à aceitação da condição imposta por ele como forma de fuga. Assim, reforçadores como notas e reconhecimento, e punidores como reprovação ou ameaça de reprovação, possibilitam que o professor estabeleça contingências para que a aluna somente produza reforçadores relacionados ao contexto acadêmico se se comportar de determinado modo, reforçando, por conseguinte, seu comportamento abusivo.

\section{Efeitos do abuso para as alunas}

Como descrito nos tópicos anteriores, os relatos das alunas ilustram diversas situações de assédio sexual, com diferentes topografias de comportamento abusivo emitidos pelos professores, porém, todos eles acentuaram o caráter aversivo dessas situações. Além disso, a análise dos relatos mostrou que o uso do controle coercitivo por parte dos professores parece ter interferido, em especial, no percurso acadêmico das alunas e na sua profissão, uma vez que, não cedendo às ameaças do professor, elas poderiam ser reprovadas, ou, como mostra este caso, ser prejudicadas futuramente no mercado de trabalho: "fico com medo de denunciar e ele sujar meu nome no mercado". Essas situações, conforme alguns relatos, levaram alunas a desistir de projetos, matérias, entre outras oportunidades acadêmicas:

Fiquei minutos ali, sentada e tentando encontrar algo que fiz, me dei conta que a minha busca era em vão pois a única coisa que me interessei 
foi pelo conhecimento que ele possuía e por me achar ignorante. Me decepcionei tanto porque ele parecia o único professor realmente interessado em me orientar na Iniciação Científica, meu projeto ficou pronto no computador, mas nunca entregue. Eu perdi totalmente a confiança nele. Morreu boa parte da minha esperança, sonhos e estímulos acadêmicos com esse episódio.

Nesse tipo de circunstância também se constitui presumivelmente o que Sidman (1989/2009) denomina "punidor condicionado", em que outras situações e eventos associados ao contexto em que o comportamento foi punido podem adquirir função aversiva. Segundo o autor, ambientes (sociais e não-sociais) em que o indivíduo é punido acabam se tornando eles mesmos punitivos, de modo que o sujeito reage a eles evitando-os completamente e aprende, assim, que o caminho mais seguro é ficar quieto. A presença do professor na universidade passa, então, a ser considerada um evento aversivo para diversos comportamentos das alunas, as quais buscam meios de se esquivar até mesmo da atenção dele: "passei a ir para faculdade com as piores roupas, o cabelo por pentear e sentava sempre no fundo da classe. Tempos depois, passei a matar aula, porque já não suportava ficar na presença dele".

Não só o professor que perpetrou o abuso se torna um evento aversivo para a aluna, mas, segundo Almeida (2017), as alunas podem trancar matérias, sentir-se "tensas" ao conversar com outros professores ou com colegas homens, e apresentar uma diminuição no rendimento acadêmico. Os casos de abuso podem afetar o desenvolvimento acadêmico a tal ponto que, de acordo com um dos relatos, uma aluna apresentou ideação suicida:

\footnotetext{
Além dele me assediar sexualmente, também me assediou moralmente com diversas ameaças incluindo me reprovar na banca de defesa de tese e ter que devolver toda a verba que recebi. Isso custou a minha saúde, fiquei extremamente doente física e emocionalmente. O pior era contar para outras pessoas e ouvir coisas do tipo: - tá reclamando do quê, homem é assim mesmo, dá logo para ele. NOJO. Pensei durante meses em suicídio.
}

Alguns efeitos do assédio sexual identificados nos relatos das alunas também se verificam na literatura acadêmica que discute $\mathrm{o}$ assunto. Estudantes que sofreram assédio sexual na universidade passam a evitar certos lugares no campus e a pessoa que emitiu o comportamento abusivo, mudam seus horários, abandonam aulas ou as frequentam menos, desistem de matérias ou cursos, tornam-se menos participativos e consideram difícil estudar e prestar atenção nas aulas (Hill \& Silva, 2005; Smit $\&$ Plessis, 2011). Além de afetar negativamente o desempenho acadêmico, universitárias que foram sexualmente assediadas relataram ter apresentado problemas para dormir, perderam a vontade de comer, deixaram de praticar esportes ou atividades específicas, precisaram encontrar alguém que pudesse protegê-las, mudaram de grupo de amigos (Hill \& Silva, 2005). Estudantes que sofreram assédio sexual também são mais duvidosos(as) de terem um relacionamento romântico feliz, são mais tímidos(as) e temerosos(as), e menos confiantes e confusos(as) sobre si mesmos(as) do que em relação a seus pares (Smit \& Plessis, 2011). Esses dados mostram que os efeitos do assédio sexual não são apenas acadêmicos, mas também psicológicos e sociais, prejudicando a vida de estudantes nos mais diversos âmbitos.

\section{Comportamentos das alunas e seus efeitos no comportamento abusivo dos professores}

Com base na análise do relato das alunas, foi verificado que, diante das situações de abuso envolvendo os professores, as alunas, em sua grande maioria (73\%), aquiesceram dizendo "não ter tido reação", ficando em silêncio, como neste caso: "Por fim, um dos mais recentes, que ao me dar um beijo de tchau em sua sala quando fui ver minha prova, encostou a boca no canto da minha. Eu simplesmente fiquei sem reação". Também houve alunas (14\%) que "bloquearam" o professor nas redes sociais, esquivaram-se dele pelos corredores, ou pararam de frequentar a sua aula: "O tempo foi passando e era torturante saber que eu teria aulas com ele, sendo assim, eu preferia frequentar as aulas raramente".

Os comportamentos das alunas de aquiescer, "bloquear" o professor nas redes sociais, evitá-lo nos corredores ou faltar às aulas, a despeito de 
terem topografias diferentes, podem, presumivelmente, ser esclarecidos pela mesma função: fugir ou se esquivar de eventos aversivos associados à situação de abuso cometido pelo professor. Contudo, esses comportamentos das alunas, se considerados agora como consequências do comportamento abusivo dos professores, podem produzir diferentes efeitos. Por exemplo, a submissão da aluna pode funcionar como um reforçador generalizado para o comportamento abusivo do professor mantendo esse operante em força; nas palavras de Skinner (1953/2003): "quando alguém foi coagido a fornecer vários reforços, qualquer indicação de sua aquiescência vem a se tornar um reforçador generalizado" (p. 88). As alunas que "bloquearam" o professor nas redes sociais, evitaram o encontro pelos corredores e pararam de frequentar as aulas, possivelmente fizeram com que o comportamento do professor passasse por um processo de esquecimento (Skinner, 1953/2003, p. 78), no qual há uma tentativa de enfraquecimento de um operante pela mera passagem do tempo, durante a qual o indivíduo não é exposto à situação em que a ação foi previamente reforçada. Nesses casos, o comportamento das alunas remove a ocasião para emissão do comportamento abusivo do professor diminuindo, assim, a frequência do comportamento, mas não necessariamente sua força, pois é provável que quando o antecedente seja reinserido (isto é, as alunas voltem a interagir pelas redes sociais, passem pelos mesmos lugares em que o professor esteja presente e frequentem suas aulas), o comportamento abusivo do professor também volte a ser emitido.

Além disso, tiveram alunas (9\%) que, conforme os relatos, confrontaram o professor ou recusaram suas propostas: "Ele pediu meu número e eu disse que não tinha celular. Disse que me daria carona para eu voltar para casa e eu disse que iria de ônibus. Ele insistiu e eu fui pra sala de aula". Por fim, houve alunas (12\%) que mencionaram ter realizado, de fato, a denúncia a instâncias da universidade:

\section{...fui até a direção e pedi providencias, para a} minha surpresa ouvi do coordenador que não era a primeira nem a ultima a levar essas reclamações até ele, entretanto nenhuma das garotas que já havia reclamado teve a coragem de levar adiante a denuncia. Eu cansei, fui diferente, denunciei.
Pautando-se na descrição das alunas, é possível conjecturar que confrontar o professor ou recusar suas propostas provavelmente fez com que o comportamento abusivo do professor passasse pelo processo de extinção, ou seja, há uma interrupção da contingência de reforçamento em que o comportamento abusivo do professor deixou de produzir as consequências reforçadoras que supostamente produzia, como a aquiescência das alunas, por exemplo. O comportamento de denunciar o abuso perpetrado pelo professor, caso a universidade tenha tomado as devidas providências, pode servir como punição para o comportamento do professor, seja positivamente - pela apresentação de eventos supostamente aversivos como uma repreensão, exposição social da situação de abuso cometido pelo professor, entre outros - ou negativamente pela retirada de eventos reforçadores associados ao cargo do professor, ou a própria perda do cargo, nos casos de exoneração. No entanto, nos relatos em que as alunas descreveram ter denunciado o professor, algumas mencionaram que a denúncia "não deu em nada”, ou não registraram na página do Facebook o que aconteceu após a denúncia ter sido feita.

Conforme a teoria skinneriana, o processo de extinção, em comparação ao procedimento de punição, parece ser o mais eficaz para reduzir a probabilidade de emissão de um dado operante (Skinner, 1953/2003). Porém, na extinção o comportamento continua acontecendo por um período de tempo mesmo após a suspensão do reforço, o que é nomeado de resistência à extinção. Uma das variáveis responsáveis pelo aumento da resistência à extinção é a quantidade de reforçamento prévio: quanto mais o comportamento foi reforçado, maior a resistência à extinção (Skinner, 1953/2003; Craig, Nevin \& Odum, 2014).

Embora não se tenha acesso à história de reforçamento do comportamento abusivo sob análise, pode-se conjecturar que esse operante é forte, uma vez que é emitido com frequência suficiente para que o indivíduo seja até mesmo identificado por esse operante (e.g., o professor é considerado "abusador"). Um dos efeitos iniciais da extinção é o aumento abrupto da frequência do comportamento e de variação topográfica. Aplicando esses efeitos aos casos em pauta, quando a aluna descreve que não cede às investidas do professor, em tese, ela não re- 
forçaria mais o seu comportamento abusivo. Com isso, virtualmente, a aluna poderia se deparar com a insistência do professor e mesmo com mudanças topográficas de caráter mais agressivo, acompanhadas por respostas emocionais de raiva e frustração, podendo expô-la a situações ainda mais violentas.

\section{Considerações Finais}

Este artigo teve como objetivo investigar, por meio da análise de relatos verbais, as contingências de dominação masculina entre professores e alunas no contexto universitário, identificando e descrevendo a topografia das ações dos professores e das alunas em situações de abuso, cometidos pelos primeiros, caracterizando também os antecedentes e as consequências de suas respectivas ações. Conforme análise dos relatos das alunas, foi possível identificar: i) comportamentos abusivos na forma de brincadeiras e piadas; ii) estereótipos de professores abusadores; iii) o caráter gradativo do abuso; iv) a proposta de sexo em troca de notas, ilustrando o manejo de reforçadores e punidores típicos do contexto acadêmico. Além disso, foram descritos, com base nos relatos, os efeitos acadêmicos, psicológicos e sociais negativos para as alunas da situação de assédio sexual, assim como os comportamentos delas perante os comportamentos abusivos dos professores, dentre os quais se destaca o comportamento de aquiescer, que pode acabar reforçando o comportamento abusivo do professor. Esses aspectos ilustram como as contingências de dominação masculina podem também se verificar na esfera universitária e como, nesse contexto, adquirem contornos específicos (relação de poder desigual entre professor e aluna, sistemas de reforçamento e punição próprios do domínio universitário) que acabam dificultando o enfrentamento desse tipo de controle social por parte das alunas.

Todas essas análises foram realizadas por meio de estratégias indiretas de investigação, pautando-se no exame de relatos, disponibilizados em uma rede social online, a respeito de situações abusivas cometidas por professores universitários. Trata-se de uma estratégia investigativa que apresenta vantagens e limitações. O estudo de redes sociais online tem ganhado espaço no campo acadêmico, e elas podem gerar registros importantes para a compreensão não só de interações sociais de pequena e grande escala, mas também de características de grupos e instituições, e até mesmo da estrutura social, ainda que haja limitações, sendo que aperfeiçoamentos metodológicos são requeridos (Marteleto, 2010; Recuero, 2014). Dessa perspectiva, a análise do relato das alunas pode ser um recurso útil para identificar práticas culturais e comportamentos relacionados a contingências de dominação masculina no contexto universitário. Além disso, a descrição de situações de assédio sexual entre professores e alunas dificilmente poderia ser obtida senão por documentos ou relatos verbais. Vale destacar ainda que o fato de os casos serem descritos anonimamente pelas próprias alunas, em um suporte como as redes sociais online, pode evitar contingências coercitivas, que alterariam os relatos das alunas como forma de fuga ou esquiva de eventos aversivos como reprovações, perseguição, entre outros.

Há, outrossim, desvantagens. Estratégias de observação indireta, como a deste estudo, apresentam limitações em comparação com a observação direta, a qual permitiria a identificação de variáveis que não fossem exclusivamente dependentes do autoconhecimento dos participantes (Luna, 2000). Considerando as restrições do próprio relato verbal para investigação de contingências, ressalta-se a importância de ampliar e diversificar as estratégias metodológicas em pesquisas ulteriores sobre temática semelhante, de modo a aprimorar e complementar as análises deste estudo. Mesmo com esses limites, a descrição, com base no exame dos relatos das alunas, das topografias de comportamento abusivo emitido por professores foi importante para auxiliar na identificação, ainda que preliminar, das diversas formas de controle coercitivo presentes nas práticas culturais de dominação masculina.

Considerando, de um lado, as relações de poder e privilégio no contexto universitário em favor dos professores, e, por outro, as possibilidades de enfrentamento de condições mais aversivas por parte das alunas quando da recusa ou denúncia do comportamento abusivo do professor, destaca-se a importância de se implementar programas na universidade que busquem não só acolher e dar os devidos encaminhamentos às denúncias, mas que garantam o anonimato da aluna, a fim de que ela não seja ex- 
posta a situações aversivas mais agudas. Sobre esse aspecto, a pesquisa de Hill e Silva (2005) mostra que mais de 35\% das alunas assediadas sexualmente não contam a ninguém, $49 \%$ contam a alguma amiga e apenas cerca de $7 \%$ denunciam para a universidade, o que sugere a insegurança das alunas quanto à efetividade da denúncia e o anonimato.

A literatura internacional indica a constituição de políticas contra o assédio sexual nas universidades, como é o caso da University of Rhode Island, na qual foi criado um Comitê de Assédio Sexual, contando com representantes de todos os setores da comunidade acadêmica, com a função de educação, defesa dos direitos das vítimas e o monitoramento de audiências formais de queixas (Keilly, Lott \& Gallogly, 1986). Em âmbito nacional, Costa (2015) destaca a formação do Coletivo Afetadas na Universidade de Brasília (UnB), iniciativa das próprias acadêmicas de criar um ambiente de escuta, suporte e auxílio para a denúncia. Segundo essa mesma autora, é importante também que as alunas participem e frequentem o DCE (Diretório Central dos Estudantes) de sua Universidade, os CAs (Centros Acadêmicos) de seus cursos, entre outros, de modo a trazer em pauta questões relacionadas ao assédio sexual e como auxiliar na criação de redes de suporte na universidade. A despeito da importância dessas políticas, Thomas (2004), amparando-se em estudos realizados nas universidades do Reino Unido, chama a atenção para o fato de que muitas delas podem exibir apenas uma função mais reativa que proativa, como uma "decoração de vitrine", com papel mais retórico do que efetivo em trabalhar para a eliminação dos casos de assédio no âmbito universitário.

Para além das questões relativas à efetividade ou não das políticas de enfrentamento de situações abusivas na universidade (ver McMahon, Wood, Cusano, \& Macri, 2019), é preciso, antes de tudo, identificar e descrever as diferentes práticas e formas de comportamentos envolvidos em contingências de dominação masculina. Trata-se, pois, de uma condição necessária para dar subsídios ao delineamento de estratégias de enfrentamento e prevenção desse tipo de controle social na universidade, com vistas a dificultar a transmissão dessas práticas opressivas na esfera educacional, buscando uma maior igualdade entre os gêneros.

\section{Referências}

Alcará, A. R., Di Chiara, I. G., \& Tomaél, M. I. (2005). Das redes sociais à inovação. Ciência da Informação, 34(2), 93-104. http://dx.doi. org/10.1590/S0100-19652005000200010.

Almeida, T. M. C. (2017). Violências contra mulheres nos espaços universitários. In S. Oliveira, C. Portela, E. Silva, C. Stevens, \& V. Zanello (Orgs.). Mulheres e violências: Interseccionalidades (pp. 384-399). Brasília: Technopolitik.

Bandeira, L. M. (2017). Trotes, assédios e violência sexual nos campi universitários no Brasil. GÊNERO, 17(2), 49-79. https://doi. org/10.22409/rg.v17i2.942

Bourdieu, P. (2010). A dominação masculina (9a ed.). Rio de Janeiro: Bertrand Brasil. (Obra original publicada em 1998).

Costa, M. B. (2015). (Re)pensando o abuso sexual em contexto universitário: Afeto, compartilhamento e a construção de fatos. (Monografia de Bacharelado em Ciências Sociais). Instituto de Ciências Sociais, Universidade de Brasília, Brasília.

Craig, A. R., Nevin, J. A., \& Odum, A. L. (2014). Behavioral momentum and resistance to change. In F. K. McSweeney \& E. S. Murphy (Eds.), The wiley-blackwell handbookof operant and classical conditioning (pp. 249-274). Malden, MA: Wiley Blackwell.

Data Popular/Instituto Avon. (2015). Violência contra mulher no ambiente universitário. Recuperado de http://www.ouvidoria.ufscar.br/ arquivos/PesquisaInstitutoAvon_V9_FINAL_ Bx20151.pdf

Figueiredo, B., \& Paiva, C. (2003). Abuso no contexto do relacionamento íntimo com o companheiro: Definição, prevalência, causas e efeitos. Psicologia, Saúde \& Doenças 4(2), 165-184. Recuperado em 13 de agosto de 2018, de http:// www.scielo.mec.pt/scielo.php?script $=$ sci_ arttext\&pid=S1645-00862003000200001\&lng= pt\&tlng $=$ pt.

Fitzgerald, L. F. et al. (1988). The incident and dimensions of sexual harassment in academia and the workplace. Journal of Vocational Behavior, 32(2), 152-175. https://doi.org/10.1016/00018791(88)90012-7 
Freitas, J. C. C., \& Morais, A. O. (2019). Cultura do estupro: Algumas considerações sobre a violência sexual, feminismo e análise do comportamento. Acta Comportamentalia, 27(1), 109-126.

Gallogly, S. M., Lott, B., \& Reilly, N. E. (1986). Sexual harassment of university students. Sex Roles, 15(7/8), 333-358. https://doi.org/10.1007/ BF00287976

Hill, C., \& Silva, E. (2005). Drawing the line: Sexual harassment on campus. Washington: American Association of University Women Education Foundation.

Hirata, H., Laborie, F., Doaré, H., \& Senotier, D. (Orgs.). (2009). Dicionário crítico do feminismo. São Paulo: Editora da UNESP.

Lei n. 12.015 de 7 de agosto de 2009. Altera o Título VI da Parte Especial do Decreto-Lei no 2.848, de 7 de dezembro de 1940 - Código Penal, e o art. 1 o da Lei no 8.072, de 25 de julho de 1990, que dispõe sobre os crimes hediondos, nos termos do inciso XLIII do art. 5o da Constituição Federal e revoga a Lei no 2.252, de 1o de julho de 1954, que trata de corrupção de menores. Recuperado de http://www.planalto.gov.br/ccivil_03/_ato2007-2010/2009/lei/112015.htm.

Lei n. 2.848 de 7 de dezembro de 1940. Dispõe sobre o crime de assédio sexual e dá outras providências. Recuperado de http://www.planalto. gov.br/ccivil_03/Leis/LEIS_2001/L10224.htm

Luna, S. V. (2000). Questionários e entrevistas como instrumentos para a coleta de informações em psicologia. Psicologia Revista, 10(1), 87-98.

Marteleto, R. M. (2010). Redes sociais e apropriações de informações: Situando campos, objetos e conceitos na pesquisa em Ciência da Informação. Tendências da Pesquisa Brasileira em Ciência da Informação, 3(1), 27-46.

McMahon, S., Wood, L., Cusano, J., \& Macri, L. M. (2019). Campus sexual assault: Future directions for research. Sexual Abuse, 31(3), 270-295. doi:10.1057/1079063217750864

Palhares, I. (2016, 13 de fevereiro). Página "Meu Professor Abusador" recebe 600 relatos de assédio. Estadão de São Paulo. São Paulo, em http:// brasil.estadao.com.br/noticias/geral,pagina-meu-professor-abusador-recebe-600-relatos-de-assedio, 10000016107.

Paracampo, C. C. P., \& Albuquerque, L. C. (2005).
Comportamento controlado por regras: Revisão crítica de proposições conceituais e resultados experimentais. Interação em Psicologia, 9(2), 227-237.

Porto, M. (2017). O enfrentamento da violência no ambiente universitário: Uma experiência na Universidade Federal do Acre. In S. Oliveira, C., Portela, E. Silva, C. Stevens, \& V. Zanello (Orgs.). Mulheres e violências: Interseccionalidades (pp. 400-411). Brasília: Technopolitik.

Recuero, R. (2014). Contribuições da análise de redes sociais para o estudo das redes sociais na Internet: $\mathrm{O}$ caso da hashtag \#Tamojuntodilma e \#CalaabocaDilma. Revista Fronteiras - estudos midiáticos, 16(2), 60-77.

Sidman, M. (2009). Coerção e suas implicações. São Paulo: Editora livro pleno. (Obra original publicada em 1989).

Silva, E. C., \& Laurenti, C. (2016). B. F. Skinner e Simone de Beauvoir: "A mulher" à luz do modelo de seleção pelas consequências. Revista Perspectiva, 7(2), 197-211. https://doi. org/10.18761/pac.2016.009

Skinner, B. F. (1973). O mito da liberdade. Lisboa: Edições 70. (Obra original publicada em 1971). Skinner, B. F. (2003). Ciência e comportamento humano. São Paulo: Martins Fontes. (Obra original publicada em 1953).

Smit, D., \& Plessis, V. du. (2011). Sexual harassment in the education sector. P. E. R./PELJ, 14(6), 173-217. doi.org/10.4314/pelj.v14i6.6

Thomas, A. M. (2004). Politicies and practice: Assessing the impact of sexual harassment policies in UK universities. British Journal of Sociology of Education, 25(2), 143-160. Recuperado de http://www.jstor.org/stable/4128679

\section{Informações do Artigo}

\section{Histórico do artigo:}

Submetido em: 13/08/2018

Primeira decisão editorial: 25/06/2019

Aceito em: 22/07/2019 